\section{A GEOGRAFIA DO VINHO / THE GEOGRAPHY OF WINE, DE BRIAN J. SOMMERS}

SOMMERS, Brian J. Geografia do Vinho. Tradução: Pamela Andrade. São Paulo: Novo Século, 2010. 237p.

ISBN: 9788576794004

\section{Adilson Rodrigues Camacho'}

O texto que ora se apresenta é resumo de um diálogo com o trabalho de Brian J. Sommers ${ }^{2}$ com base tanto no que encontrei de muito positivo, e que reafirmo, quanto no que identifiquei como falta, caminhos e raciocínios supostos pelo que foi posto, propiciando a maior das ousadias cabíveis ao leitor: realizar sucessivas sínteses implicadas no texto sob controle muito relativo de autor e leitor; tudo apenas possível porque o texto foi escrito e publicado. Caminhamos pelas informações gerais sobre o autor e seu livro, seguimos por brevíssimos comentários dos dezoito capítulos, procurando um lugar para concluir. Logo no primeiro capítulo, o autor, a título de introdução, dá conta de onde ele e seu tema vieram, e de como ambos tornam-se livro. Suas

1 Professor titular na Faculdade Armando Alvares Penteado (FAAP) e na Universidade Paulista (UNIP). arocamacho@gmail.com

$\triangle$ Universidade Paulista, Faculdade de Administração, Av. Dr. Altino Arantes, 1344, Santa Cruz. 04042-035. São Paulo, SP.

2 Brian J. Sommers é professor do Departamento de Geografia da Universidade Central do Estado de Connecticut, New Britain, <Sommersb@ccsu.edu>. É Ph.D. em Geografia com título em Planejamento Urbano pela Universidade de Arizona (1995). O título da tese é "O impacto do meio ambiente amenidades de estabilidade residencial urbano: um estudo de caso de Cleveland, Ohio". Seu mestrado (M.A.) em Geografia foi pela Universidade de Miami (1989), com o trabalho "Cityof Orrville Estágio Planejamento". O bacharelado foi em Geografia, na Universidade de Akron, Akron, Ohio (1987). As informações sobre o autor são aquelas prestadas pelo próprio no primeiro capítulo do livro e no Curriculum público, disponível em: <http://www.geography.ccsu.edu/sommers/ Sommers\%20Educational\%20Administration\%20Vita.pdf>. Acesso em:1 set. 2011.
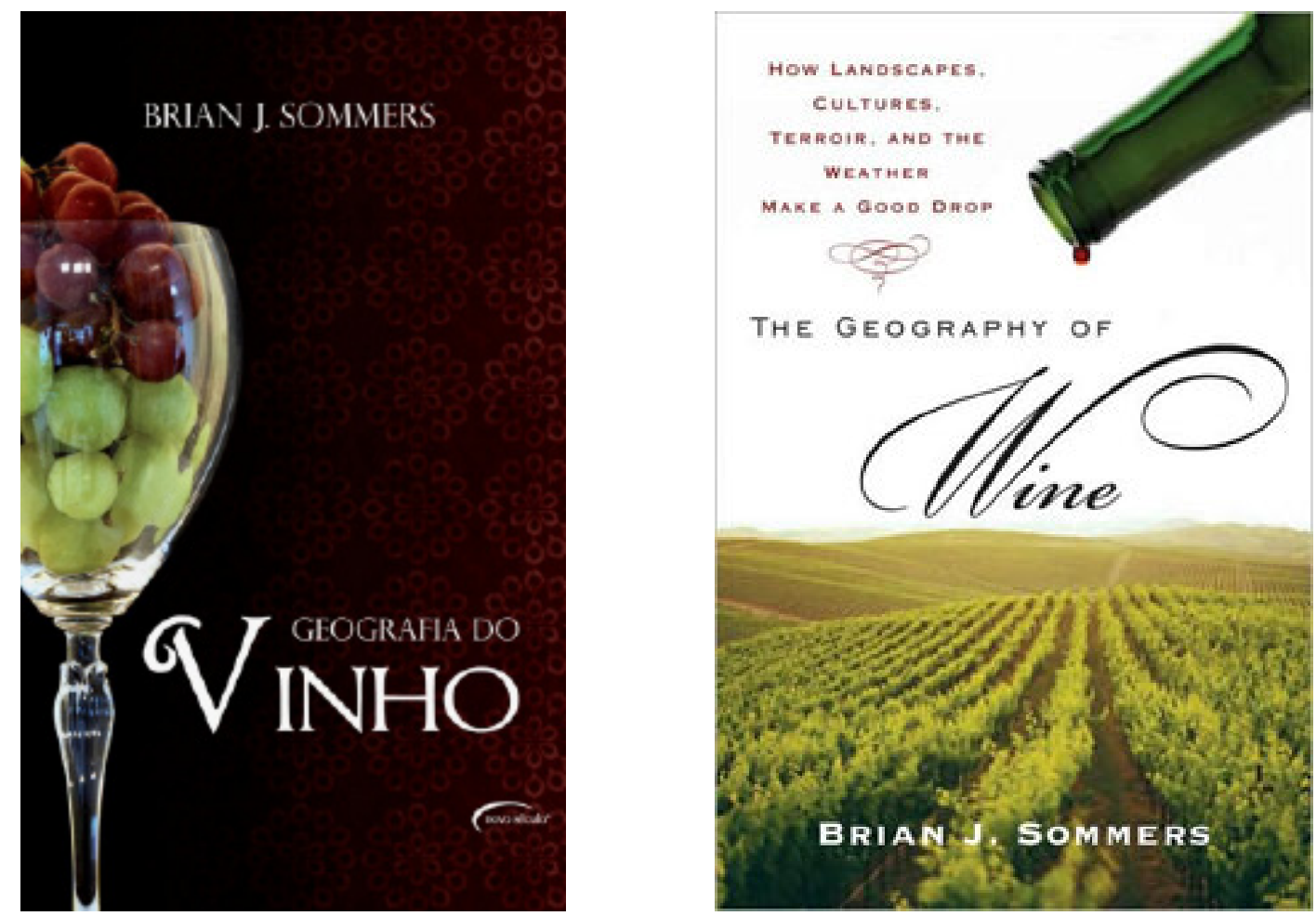

principais áreas de interesse são: planejamento, turismo e, é claro, vinhos. Gradua-se em geografia na Universidade de Akron, em Ohio, nos Estados Unidos da América, fazendo mestrado e tomando contato com o mundo dos vinhos nas aulas de "Geografia do vinho", de John Dome, na Universidade de Miami, doutorando-se em Connecticut, sendo aí professor e pesquisador na Central Connecticut State University (CCSU). Descreve suas experiências no universo vinífero de modo bem prosaico, até com certa informalidade, trazendo-as ao texto em alguns momentos (p. 11, 116).

O Professor Brian J.Sommers tem ligações com o Brasil, participando de convênio entre a Central Connecticut State University (CCSU) e a Universidade Federal do Rio Grande de Sul (UFRS) e a Universidade do Estado de Santa Catarina (UESC) desde 2007, no qual suas 
responsabilidades incluem a manutenção de vínculos institucionais, supervisionar estágios de estudantes e as transferências de crédito, promovendo programas de intercâmbio de estudantes e professores e elaborando relatórios sobre as atividades do Center for International Education (CCSU). Também integrou o Consórcio de Desenvolvimento Urbano entre Bridgewater State College e as universidades citadas (UFRGS e UESC) de 2006 a 2010, atuando para o Fundo para a Melhoria da Educação dos Estados Unidos da América subordinado ao Departamento de Educação deste país.

O livro foi traduzido para a língua portuguesa na seguinte apresentação: SOMMERS, Brian J. Geografia do vinho. Tradução: Pamela Andrade. São Paulo: Novo Século, 2010. 237 p. ISBN: 9788576794004, de fácil acesso. (Original em inglês: SOMMERS, Brian J. The geography of wine: how landscapes, cultures, terroir, and the weather make a good drop. Paperback, Plume Press-Penguin PrenticeHall, 2008. De difícil acesso, encontrado apenas nas grandes livrarias e sob encomenda.)

É a versão brasileira que utilizamos para a resenha, portanto, é necessário registrar que além de inúmeros erros, principalmente ortográficos (provavelmente de tradução e de impressão), há discrepância na combinação dos elementos gráficos da capa com o título do livro (o subtítulo foi retirado), tão expressiva na edição original em que são mutuamente referentes (fotos, imagens, título e subtítulo). É de se perguntar sobre o papel e a responsabilidade da editora na revisão técnica da tradução, quanto à fidelidade nos mínimos detalhes?

3 Na consulta ao site da editora Novo Século, há um "subtítulo" provavelmente promocional anunciado para o livro: "Um passeio único pelos vinhedos ao redor do mundo"; entretanto, o mesmo não consta em nenhum lugar na tradução deste.
O autor cita preconceitos dirigidos à geografia, registrando que as pessoas, em geral, estão muito distantes da ciência geográfica, afirma que "geralmente ficam completamente perdidas ao explicar o que é geografia" e, como instrumento educacional contra tal ignorância geográfica, o autor oferece a geografia ciência, com suas disciplinas acadêmicas tornadas capítulos (p. 12). Faz, também, referência de modo assistemático, a geografia realizada de modo inconsciente, cotidianamente (p. 10). Esta, de caráter existencial, cujos fazeres e saberes banais compõem-se com o mundo da vida, tratando dos vínculos entre fazeres, lugares, produtos e mercadorias vinícolas.

O livro constitui-se de capítulos apresentados como aulas introdutórias de disciplinas normalmente ministradas em um curso de geografia (geografia econômica, geografia política, geografia cultural, geografia urbana, biogeografia, etc.), com um tema articulador de conteúdo: o vinho. A propósito, afirma que o vinho é um assunto como qualquer outro para o exercício da abordagem geográfica. Na esteira das considerações sobre seu tema de pesquisa, Brian J. Sommers afirma que "geógrafos tendem a pensar muito em termos de temas e de lugares" (p. 10). Aqui é colocado assunto delicado da construção teórica da geografia: o tema traz a realidade objetivada e selecionada de modo horizontal, enquanto o lugar, a região traz aquilo que se deseja verticalmente. $\mathrm{O}$ autor defende a primazia dos estudos de geografia

4 Segundo Armando Corrêa da Silva, a geografia é uma subtotalidade (SILVA, 2000) e, assim posta como analítica e existencial, viabiliza-se como reflexão e fazer numa forma mediatizada por ações que produzem as condições para a vida, aqui, o vinho como uma delas, escolhido por Brian J. Sommers como mote da conexão das abordagens geográficas em sua vertente analítica, científica, posto que suas múltiplas dimensões permitam tratar das dimensões sociais da realidade. A forma posta pelo autor, para nós se completaria, então, com a possibilidade do vinho conferida pelas mesmas relações de trabalho, pela arte e pela técnica, mas como vivências de raízes profundas e símbolos de enraizamento, mas também pelos investimentos, produção industrial, logística e desenraizamento. 
com base temática (normalmente mais gerais), embora não descarte estudos regionais, empregando-os, aliás, como exemplos e aplicação dos conceitos principais em todos os capítulos.

A abordagem geográfica leva à discussão do conceito de terroir, pois é tão importante que o autor afirma que os capítulos são abordagens das dimensões do terroir (p. 24), e seus objetivos são "entender a geografia do vinho", o "conhecimento sobre terroir e sua importância". E ao falar de seu país, declara o porquê do próprio livro: estimular nossa curiosidade quanto aos lugares è diversidade de seus produtos, escolhendo o vinho no contato com seus processos localizados ( $p$. 204).

É preciso registrar que seu texto é uma introdução, nos níveis teórico e prático, à geografia consolidada, tendo no geógrafo, de posse do escopo da disciplina, o sujeito analítico da abordagem científica e no vinho, o objeto de interesse e produto do trabalho que se espacializa e, embora pudéssemos tratar da geografia como movimento de conhecer e o vinho experiência e técnica com maior aporte da geografia cultural, como dimensão espacial da existência de emaranhados nas práticas do sujeito a domesticação do ambiente, manejo do terreno, cultivo de plantas, hábitos, costumes e criação de animais, tudo virando paisagem ou geografia vivida, o outro lado da geografia (ciência) predomina como geografia econômica na maior parte dos capítulos, mas todos tratam do caráter essencialmente espacial da relação entre ser humano e natureza, expresso nos usos territoriais; e todos eles localizam as ações e produções dos seres humanos.

Usos também suscitam escalas da existência: lugar (base material e imaterial da vida), território (âmbito do possuir e do defender), paisagem (consolidações temporais dos fazeres); também gestão e

Geograficidade | v.2, n.1, Verão 2012 ISSN 2238-0205 planejamento: administração e projeção de estratégias da produção em todos os momentos da cadeia.

O texto desenvolve-se entre didático e ensaístico5, com mais ênfase naquele. Quanto ao primeiro atributo, uma característica importante do texto é ancorar a maior parte dos capítulos em clássicos do pensamento geográfico, sendo ou não geógrafos, todavia todos com contribuições fundamentais ao seu desenvolvimento como disciplina acadêmica: Willian Pattison (Capítulo 1), Wilhelm Köppen (Capítulo 3), Johann von Thünen (Capítulos 7, 8, 14, 15), Walter Christaller (Capítulo 12) Carl Sauer (Capítulo 2), Charles Darwin (Capítulo 7), oferecendo oportunidades de contato com esses importantes autores e seus trabalhos aos leigos, para falar em vinho, em geografia científica.

E na frase "o vinho é mais do que sabor, essência e aparência" (p. 9), o autor remete à geografía envolvida em todo o ciclo produtivo do vinho, não apenas em suas características gustativas, culturais ou enológicas, mas também à estrutura fundiária, escolha e manejo do terreno de cultivo da vitis vinifera (uva própria à vinificação), distribuição e consumo do produto perfazendo o conjunto de usos e, portanto, território; processo responsável pela emergência do corpo e da alma do vinho como artefato. O termo "essência", aqui, é de uso comum, referindo-se mais aos significados e conhecimentos de seu fabrico.

O professor Brian é bem claro quanto àquilo que apresenta. Há apenas alguma ambiguidade quanto à posição que adota diante da controvérsia entre estandardização e manutenção da tradição no que

5 O gênero da obra é não ficção, tratando de geografia geral (o tema universal e passível de padronizações) e regional (descrição da viticultura e de suas regiões particulares), além das subáreas da geografia econômica (agrária, industrial, das cidades, dos transportes), cultural (dos costumes, tradições regionais), geografia regional (urbana, rural). 
diz respeito à viticultura, e as críticas que lhe são dirigidas parecem em parte oriundas da incompreensão de suas propostas (de oferecer um livro sobre os vários aspectos da geografia que são parte da explicação do vinho) e em parte pela falta de mapas do livro (leitura a ser complementada cartograficamente por material extra ${ }^{6}$, o que lembra a todo momento); nos dois casos, os ataques são depreciativos e facilmente explicáveis pela inadequação entre interesses de leitores e a linha editorial escolhida, pois explica: "há livros sobre a história do vinho, livros que falam sobre degustação, qualidade e valor de vinhos antigos, regiões específicas, plantação de uvas, além da produção e culinária em que o vinho é utilizado. [e] livros para os ignorantes no assunto, atlas do vinho e ensaios fotográficos de vinhedos". (p. 10).

Faz questão de deixar claro em que segmento editorial do mundo vinícola está inserido seu livro, pois "é uma introdução aos princípios geográficos que proporcionam uma melhor compreensão sobre o vinho", sendo "um ótimo acompanhamento para todos os outros livros sobre vinho que você possui em sua estante". Sublinha que sua proposta não se enquadra em nenhuma das categorias de técnicos ligados à cadeia produtiva do vinho, assinalando sua contribuição como geógrafo7, com base na concepção de que "a geografia é um meio para

6 Recorri constantemente aos Atlas de Johnson; Robinson (2008); Stevenson (2005) e para fotos e imagens de rótulos, vinhedos e vinícolas, ao livro editado por Becket (2008).

7 O livro de Brian J. Sommers merece diálogo com suas justificativas de sua proposta, pois a um só tempo admite faltas de que o acusam e declara tanto sua relativa ignorância como enólogo ou degustador quanto à necessidade de acompanhamento do texto com mapas, desenhos, croquis, enfim, material cartográfico não contido no livro, mas ao qual o autor remete a todo momento! Por razões editoriais (segmento de mercado, custo...), estéticas e técnicas (não é possível colocar os "mapinhas' cobrados por leigos em cartografia, quando se dá conta da qualidade dos atlas confeccionado em alto níve em termos de cores, informações cartográficas, papel, parâmetros geodésicos, agrimensura, topográficos, etc.), posto que assim, seria outro trabalho. entender como algo funciona" (p. 12), deixando, assim, patente sua visão de geografia ${ }^{8}$, e passa a listar as perguntas que o geógrafo deve encaminhar e responder. (p. 12-13). E, visivelmente inspirado em Hugh Johnson", tal geografia deve levar a "ver e até sentir o sabor de sua influência" na garrafa de vinho. (p. 9).

Em linhas gerais, os capítulos apresentam análises basicamente ambientais, culturais e econômicas como parâmetros das sínteses geográficas, seu objetivo. São dezoito capítulos compostos por duas partes: a primeira apresenta os temas particulares de uma garrafa a serem explorados na segunda, que traz uma aplicação ou demonstração regional dos conceitos.

A sequência de capítulos do texto é a seguinte:

Capítulo 1: "A geografia e o estudo do vinho"

Capítulo 2: "Paisagens e regiões do vinho"

Capítulo 3: "A climatologia e a viticultura"

Capítulo 4: "Microclimas e vinho"

Capítulo 5: "Uvas, solo e terroir"

Capítulo 6: "Biogeografia e uva"

Capítulo 7: "Viticultura, agricultura e ameaças naturais"

8 Inserir como nota de rodapé: Que pode ser contestada, por ser acentuadamente positivista em alguns momentos, embora seja muito eficaz, ao menos nesse nível da divulgação científica, para que serve a geografia, sem rodeios. Ele afirma: "Nós olhamos para o mundo a nossa volta e desvendamos como ele funciona" (p. 12-13).

9 Inserir nota de rodapé: Nas próprias palavras do autor, mostrar a "boa quantidade de geografia por trás de toda garrafa de vinho" (parece haver realmente influência de $\mathrm{H}$. Johnson). E, ao anunciar seu duplo objetivo, para o geógrafo não são duas coisas a geografia envolvida no ciclo do vinho (seja arte ou mercadoria) e seu estudo (daí seu caráter didático...) e por isso associo ambos de modo complementar, pois Hugh Johnson, tanto no livro 1001 vinhos para beber antes de morrer (p. 6-9), quanto no Atlas mundial do vinho (p. 6C), afirma que cada garrafa é única (assim como a experiência a cada taça), mesmo quando considerados vinhos de mesmo vinhedo, lote, mesma uva, safra, e em razão de tudo que the pode acontecer durante seu percurso até o copo, como propriedades e comportamento da rolha, temperatura, qualidade do armazenamento, transporte, entre uma lista surpreendente para o leigo. 
A Geografia do Vinho / The Geography of Wine, de Brian J. Sommers

Capítulo 8: "Viticultura e os sistemas de informação geográfica" Capítulo 9: "Produção de vinho e geografia"

Capítulo 10: "Difusão do vinho, colonização e geografia política"

Capítulo 11: "Urbanização e geografia do vinho"

Capítulo 12: "Geografia econômica e vinho"

Capítulo 13: "Comunismo, geografia e vinho"

Capítulo 14: "A geografia e os concorrentes do vinho"

Capítulo 15: "Vinho, cultura e geografia da sobriedade"

Capítulo 16: "Identidade regional, vinho e multinacionais"

Capítulo 17: "Regionalismo e turismo do vinho"

Capítulo 18: "Até onde o vinho pode me levar"

\section{CONCLUSÃO}

Caberia considerar que, ao final do livro, senti prazer com a leitura que muito me inquietou. Fez-me pensar na geografia como um todo a partir da consideração crítica do terroir. Porém, penso que não se pode fazer "boa ciência" sem politizar as questões. Por exemplo: como empregar mais trabalho com o vinho? Como tomar vinho, todo mundo? Como nos beneficiarmos desse tipo de estudo e construir um campo de debates com base no curso proposto por Brian J. Sommers?

As contradições entre rótulos varietal e regional (p. 210) são expressões de um debate que antes de ser feito perde terreno ao embate, por razões econômicas de concorrência internacional. A começar pelo aplanamento intelectual da classificação por variedade de uvas, o vinho varietal, pois o registro da região nos rótulos europeus implica conhecê-la, requer muita geografia! Debate que atrai outro, então, que é teórico e epistemológico, com os lados: os produtos como o vinho, ao se tornarem mercadoria em escala global, perdem, todos, sua singularidade, interessando à geografia, hoje, o estudo da homogeneização do mundo, uma disciplina com referencial histórico de feições de regiões e de fazeres no passado? Ou tal singularidade é dado ontológico do real por mais que a economia mundial rebaixe e aplaine formas culturais? E quando a região vivida será apresentada como tal, distinta da região geométrica, ambas importantes, mas não iguais?

$$
\text { Boa leitura! }
$$

\section{REFERÊNCIAS}

BECKET, Neil. (prefaciado por Hugh Johnson). 1001 vinhos para beber antes de morrer. Rio de Janeiro: Sextante, 2008.

JOHNSON, Hugh; ROBINSON, Jancis. Atlas mundial do vinho. Rio de Janeiro: Nova Fronteira, 2008.

SILVA, A. C. A aparência, o ser e a forma (geografia e método). GEOgraphia, Ano II, n. 3, 2000. p. 7-25.

STEVENSON, Tom. The new sotheby's wine encyclopedia. London: Dorling Kindersley Limited, 2005. 